\title{
COMBINED DEVICE FOR MAGNETIZATION AND DEMAGNETIZATION OF PRODUCTS MADE OF MAGNETIC MATERIALS
}

\author{
Hovhannisyan Andranik Tarik \\ candidate of technical Sciences, assistant professor, \\ Bareghamyan Gurgen Wirab \\ doctor of technical Sciences, professor, \\ Grigori Pitkevich Ilyich \\ engineer, \\ Khachatryan Vahe Hayk \\ scientific collaborators, \\ Arzanyan Ruben Gagik \\ scientific collaborators, \\ Azatyan Rafael Gevorg \\ scientific collaborators \\ National Polytechnic University of Armenia, \\ Yerevan \\ КОМБИНИРОВАННОЕ УСТРОЙСТВО ДЛЯ НАМАГНИЧИВАНИЯ И РАЗМАГНИЧИВАНИЯ \\ DOI: $\frac{10.31618 / \text { nas. 2413-5291.2020.2.53.16 }}{\text { ИЧЗНИЯ РАЗНИИВНИЯ }}$ \\ ИЗДЕЛИЙ ИЗ МАГНИТНЫХ МАТЕРИАЛОВ
}

\author{
Оганесян Андраник Тарикович \\ кандидат тех. наук, доцент, \\ Барегамян Гурген Вирабович, \\ доктор тех. наук, профессор, \\ Григори Питкевич Ильич \\ инженер, \\ Хачатрян Ваге Айкович \\ научный сотрудник, \\ Арзанян Рубен Гагикович \\ научный сотрудник, \\ Азатян Рафаел Геворкович \\ научный сотрудник \\ Национальный политехнический университет Армении, \\ 2. Ереван
}

\section{Annotation}

A combined device for magnetizing and demagnetizing products made of magnetic materials, in particular permanent magnets, has been developed and manufactured in accordance with the specified modes of magnetization and demagnetization, which provides control of parameters on the display screen.

\section{Аннотация}

Разработано и изготовлено комбинированное устройство для намагничивания и размагничивания изделий из магнитных материалов, в частности постоянных магнитов, которое соответствует заданным режимам намагничивания и размагничивания и обеспечивает мониторинг параметров на экране дисплея.

Keywords: magnetization, demagnetization, magnetic material, installation, electromagnet, microcontroller, monitoring, display.

Ключевые слова: намагничивание, размагничивание, магнитный материал, установка, электромагнит, микроконтроллер, мониторинг, дисплей.

Введение. В машиностроении, приборостроении и в других отраслях промышленности постоянно осуществляется намагничивание и размагничивание элементов и приборов из ферромагнитных материалов, в частности постоянных магнитов. Нами спроектировано, изготовлено и испытано комбинированное устройство для намагничивания и размагничивания постоянных магнитов, удостоенное патента РА на изобретение [8].

Основой для представленного устройства служили разработанные авторами в течение многих лет устройства для намагничивания и размагничивания, а также научно- исследовательские работы в данном направлении [1 - 7].

Анализ разработанных ранее устройств, в том числе известных из литературы, показал, что все эти устройства имеют два основных недостатка. Во-первых, протекаемые в них процессы намагничивания и размагничивания изделий из магнитных материалов осуществляются разными устройствами, функционирующими в фиксированном режиме и предназначеними для полного намагничивания и размагничивания определенных изделий. Во-вторых, в этих устройствах максимальная напряженность магнитного поля обусловлена амплитудой 
питающего напряжения и параметрами индуктивной катушки намагничивания, не обеспечивается также мониторинг электрических параметров.

Целью настоящей работы является разработка, проектирование и изготовление устройства, позволяющего в зависимости от материала изделия, осуществить полное или частичное намагничивание и размагничивание изделия посредством комбинированного многорежимного устройства, обеспечивая мониторинг режима и параметров индуктивной катушки.

Решение задачи. Упрощенная структура рассматриваемого комбинированного многорежимного устройства показана на рис. 1.

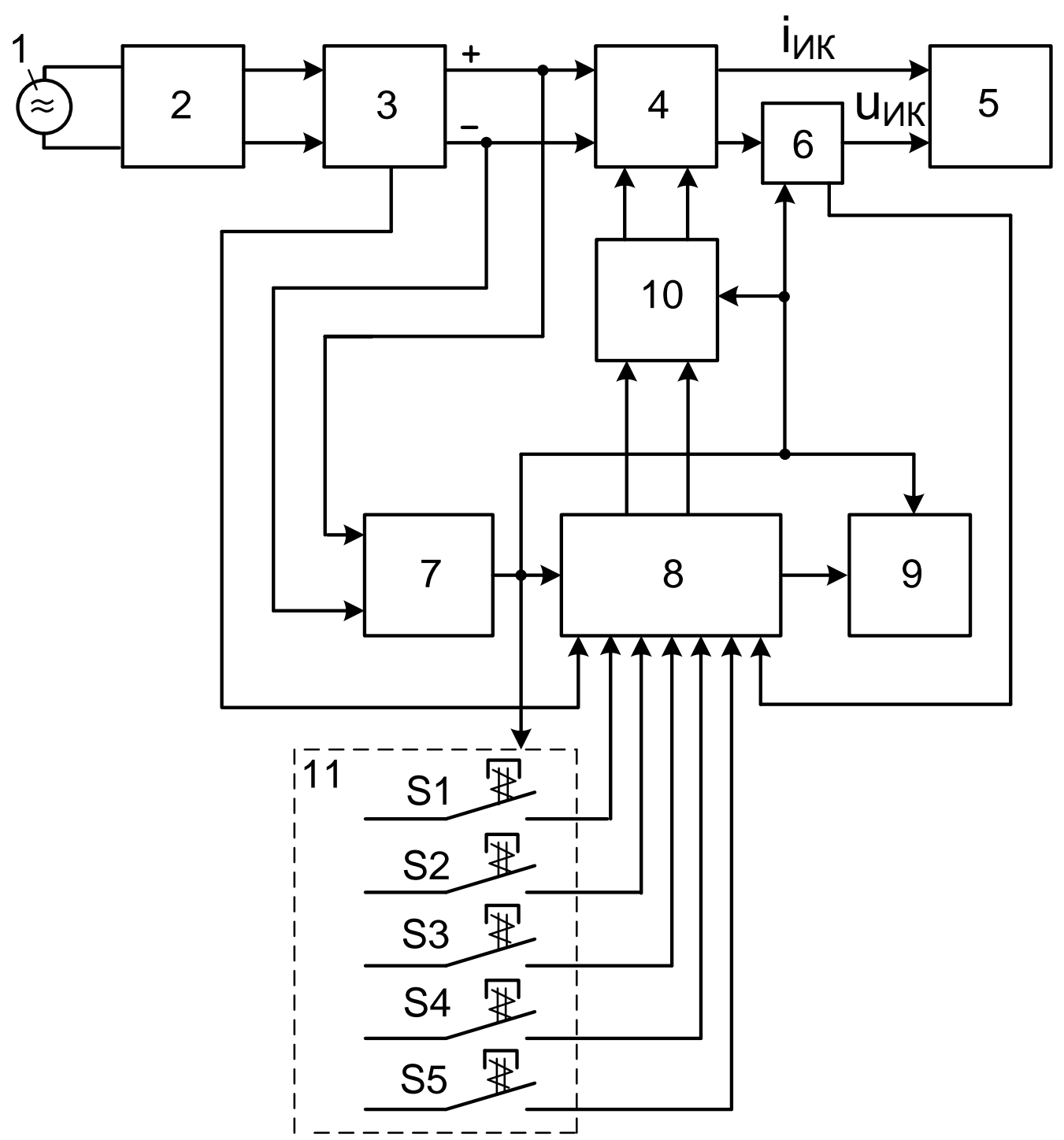

Рисунок 1. Упрощенная структурная схема устройства

Устройство питается от источника однофазного переменного напряжения 1 и содержит: диодный мостовой выпрямитель со сглаживающим фильтром 2, датчик напряжения 3 , электронный мостовой преобразователь 4, индуктивную катушку (ИК) намагничивающего электромагнита 5 , датчик тока $\mathrm{i}_{\text {ик }}$ (ДТ) индуктивной катушки 6, источник питания постоянного напряжения 7, микроконтроллер (МК) 8, монитор 9, усилитель мощности (УМ) сигналов управления 10 и электрические кнопки S1 ...S5 самовозврата 11.

На рис. 2 показаны временные диаграммы тока индуктивной катушки $\mathrm{i}_{\text {ик }}$ в процессе намагничивания и размагничивания, анализ характеристик которых дан в $[1,2,5]$. 


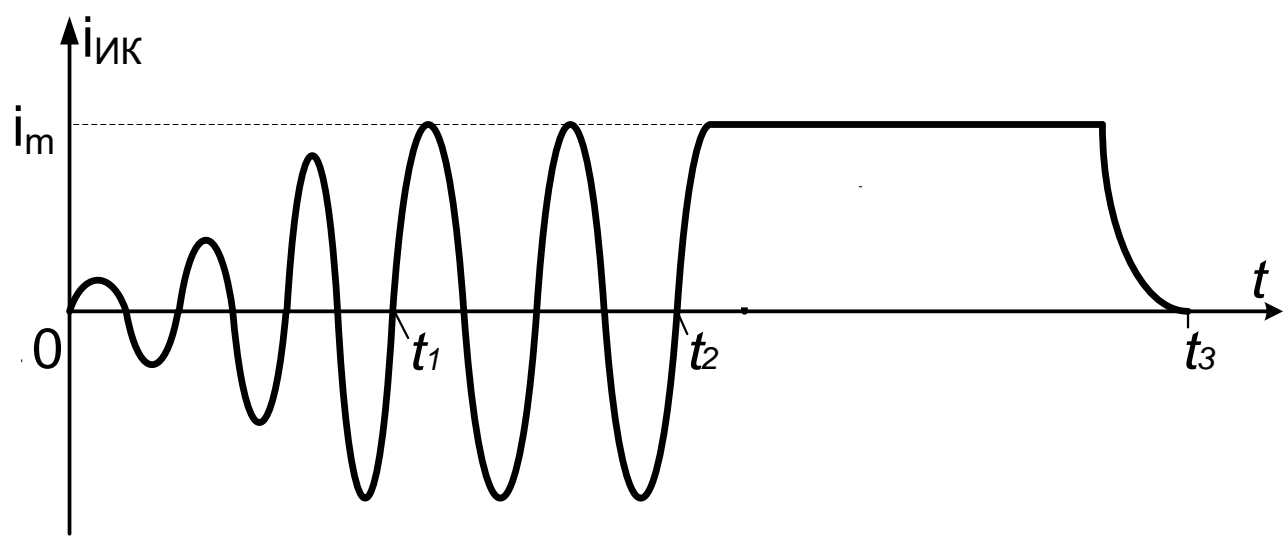

a)

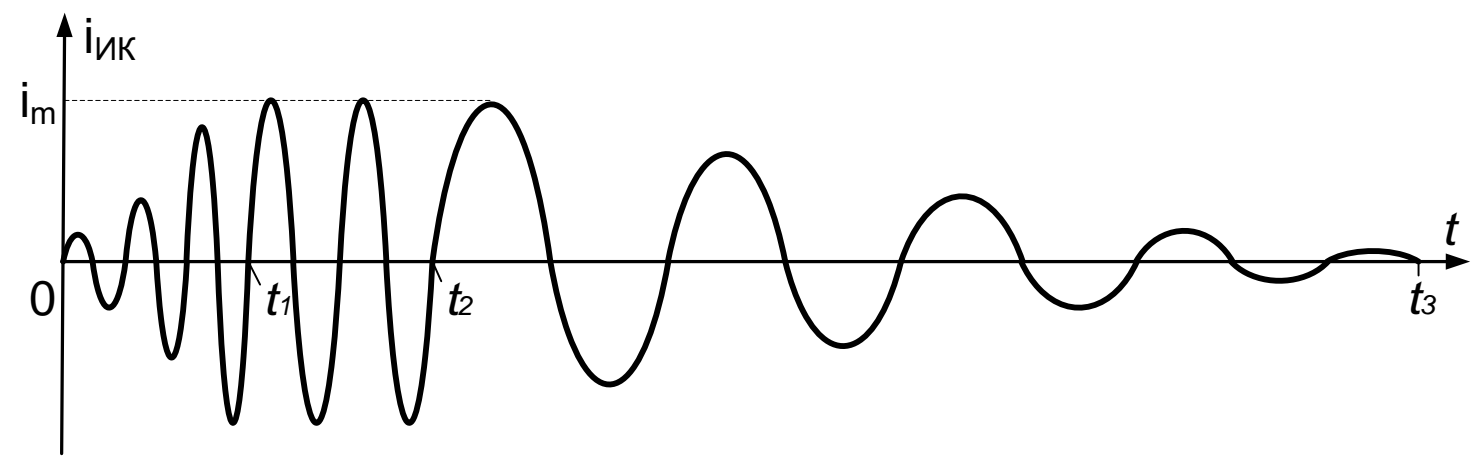

б)

Рисунок 2. Временные диаграммы тока индуктивной катуики в проиессе намагничивания (а) и размагничивания (б)

Для полного либо частичного намагничивания или размагничивания магнитного изделия соответствующие режимы и параметры задаются извне посредством кнопок S1...S4. В зависимости от типа материала в МК вводятся соответствующие режимы, физические величины и их значения, обеспечивая при этом соответствующий режим и параметры для индуктивной катушки. Посредством кнопки S3 цифровые значения физических величин уменьшаются, а посредством кнопки S4- увеличиваются. Посредством кнопки S5 устройство запускается.

Мониторинг вводимых параметров, их цифровых значений, а также электрических параметров индуктивной катушки осуществляется с помощью данных, выводимых на экран дисплея. Работа МК обеспечивается соответствующим программным обеспечением.
Электрическая
схема
мостового транзисторного преобразователя приведена на рис. 3. 


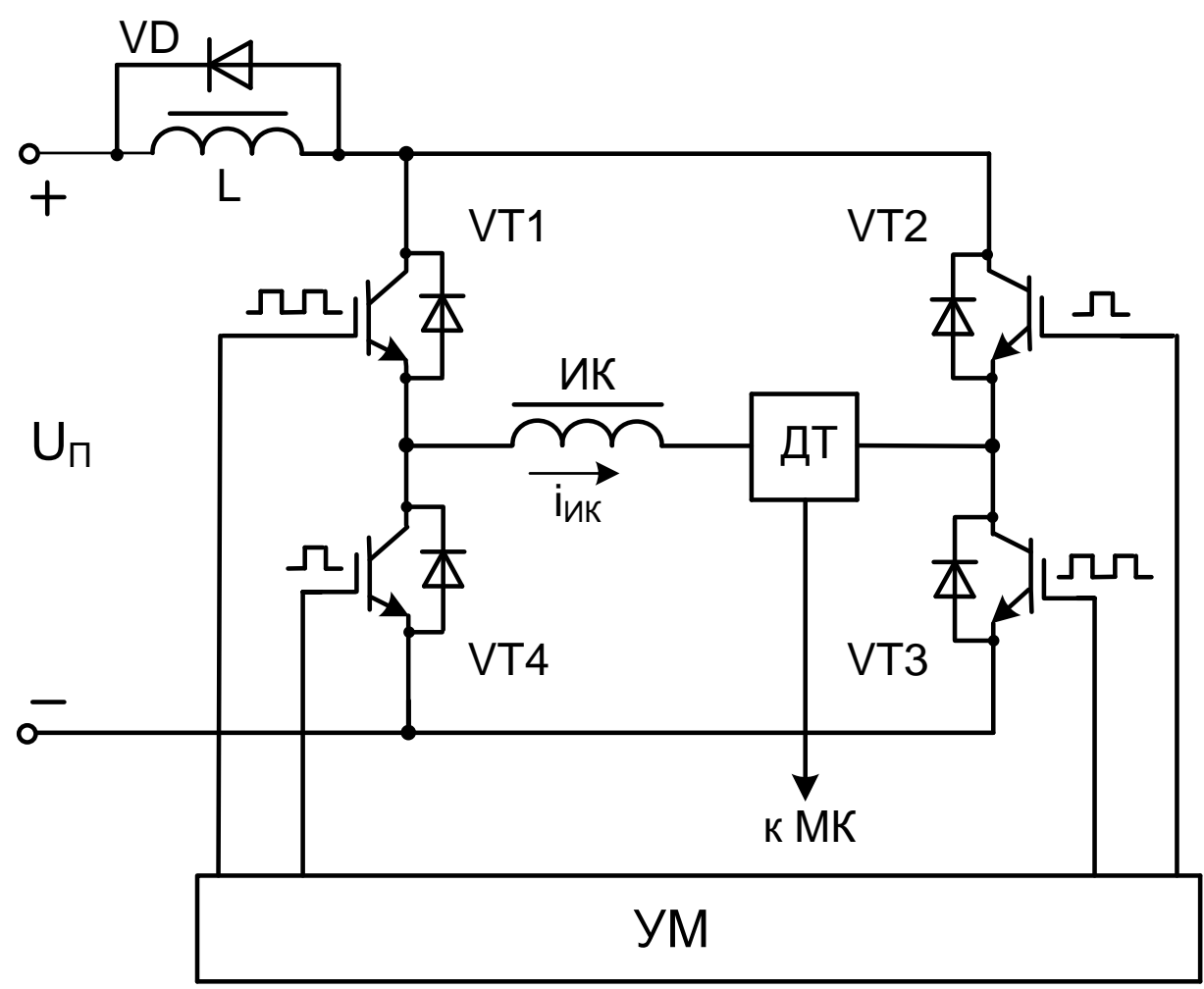

Рисунок 3. Электрическая схема мостового транзисторного преобразователя

Источник входного однофазного переменного напряжения обеспечивает напряжение необходимой величины и мощности для работы устройства, которое подается на диодный мостовой выпрямитель. С помощью этого выпрямителя выпрямляется и фильтруется входное переменное напряжение, обеспечивая близкое к ее амплитуде постоянное напряжение. Величина постоянного напряжения контролируется датчиком напряжения, и при ее выходе за допустимые пределы вырабатывается соответствующий сигнал, подаваемый на МК. Электронным преобразователем постоянное напряжение преобразуется в переменное, и посредством намагничивающей катушки электромагнита создается электромагнитное поле необходимой величины и характеристики. Датчиком тока контролируется ток через индуктивную катушку, и при его превышении заданного значения формируется соответствующий сигнал, подаваемый на МК. Источник питания постоянного тока обеспечивает напряжения необходимых уровней для питания датчика тока, МК, дисплея, усилителя управляющих сигналов и кнопок самовозврата. Соответствующим компьютерным программированием МК управляется работа отдельных узлов. На экране дисплея отображаются соответствующие физические величины и их значения, а усилителем управляющих сигналов усиливаются по мощности импульсы управления транзисторами мостового преобразователя.

Устройство работает следующим образом. Изделие из магнитного материала помещается в воздушный рабочий зазор электромагнита. Устройство подключается к источнику однофазного переменного напряжения. МК входит в режим мониторинга, и на экране дисплея отображается значение частоты $\mathrm{f}_{1}$. Здесь и далее посредством кнопок S3 или S4 задается цифровое значение заданной и отображаемой величин.

Нажатием кнопки S1 MК переводится в режим частоты $\mathrm{f}_{1}$ c длительностью $\mathrm{t}_{1}$, а нажатием кнопки S2 на экране дисплея отображается начальное цифровое значение $\mathrm{t}_{1}$.

Нажатием кнопки S1 MК переводится в режим частоты $\mathrm{f}_{2}$, а нажатием кнопки S2 на экране дисплея отображается начальное цифровое значение $\mathrm{f}_{2}$.

Нажатием кнопки S1 MК переводится в режим частоты $\mathrm{f}_{2}$ с длительностью $\mathrm{t}_{2}$, а нажатием кнопки S2 на экране дисплея отображается начальное цифровое значение $t_{2}$.

Нажатием кнопки на S1 MK переводится в режим частоты $\mathrm{f}_{3}$, а нажатием кнопки $\mathrm{S} 2$ на экране дисплея отображается начальное цифровое значение $\mathrm{f}_{3}$.

В режиме намагничивания изделия задается $\mathrm{f}_{3}=0$.

Нажатием кнопки S1 MК переводится в режим частоты $\mathrm{f}_{3}$ с длительностью $\mathrm{t}_{3}$, а нажатием кнопки S2 на экране дисплея отображается начальное цифровое значение $\mathrm{t}_{3}$.

Нажатием кнопки S1 MК переводится в режим электрического параметра индуктивной катушки. Для задания амплитудного значения $\mathrm{i}_{\text {ам }}$ тока $\mathrm{i}_{\text {ик }}$ катушки нажимается кнопка S2, а для задания амплитудного значения его напряжения $\mathrm{u}_{\text {ик }}$ повторно нажимается кнопка S2, и на экране дисплея отображается начальное цифровое значение соответствующей величины. 
Нажатием кнопки S1 MK переводится в режим мониторинга электрических параметров индуктивной катушки для индикации на экране дисплея значения соответствующего параметра во времени t. Для слежения во времени за значением

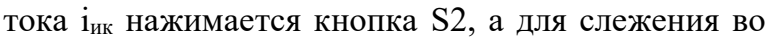

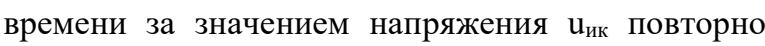
нажимается кнопка S2. Без привлечения кнопки S2 на экране дисплея отображаются значения частот $\mathrm{f}_{1}$ $\ldots \mathrm{f}_{3}$ во времени.
Нажатием кнопки S1 MК выводится из режима мониторинга, нажатием кнопки S5 запускается заданный процесс для изделия с соответствующим режимом и параметрами. По завершении процесса устройство возвращается в исходный режим.

Фотоснимок разработанного и изготовленного устройства показан на рис. 4. Устройство получило название DeMag-3 и прошло удачное испытание.

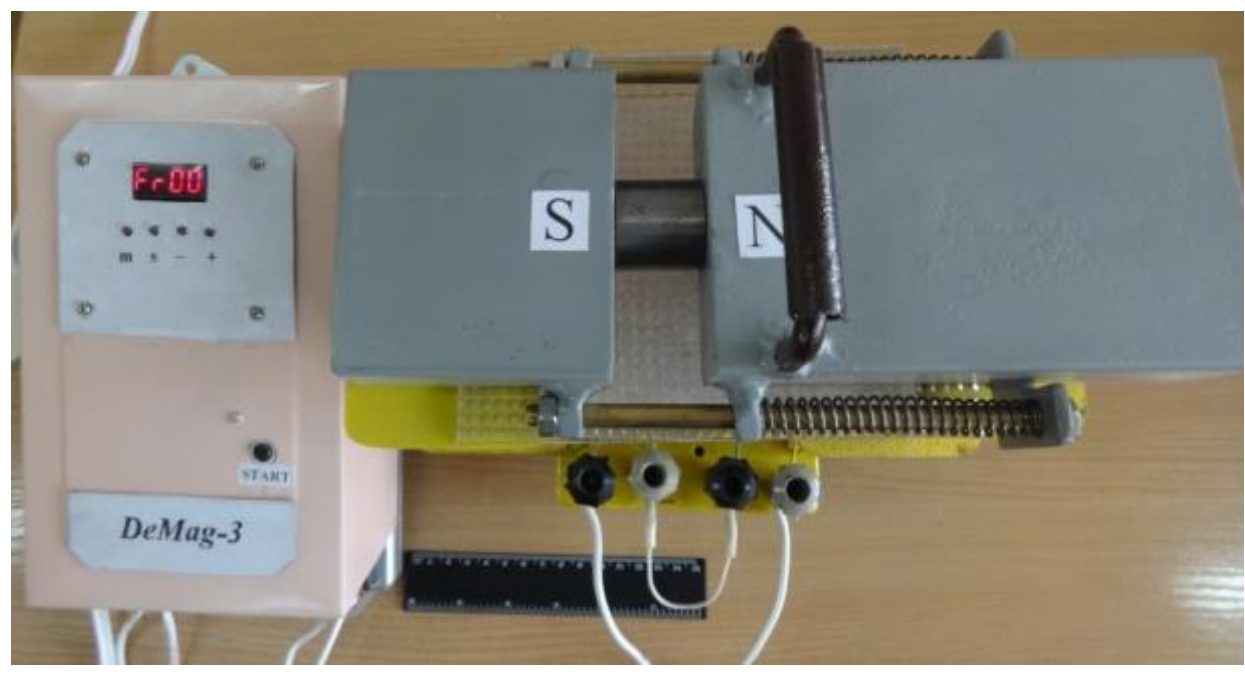

Рисунок 4. Фотоснимок устройства

Структура и основные параметры электромагнита, примененного в устройстве, даны в [5]. В качестве электромагнита может быть применена также установка рассмотренная в [2-4].

В устройстве использован МК серии ATMEGA16PU, в мостовом преобразователе применены силовые IGBT транзисторы типа IKW75N60H3, датчик тока типа CAS 50-NP, входной дроссель L шунтирован диодом марки FESF16JT, а индуктивность дросселя составляет $47 . \mu \kappa \Gamma$.

Заключение. C помощью предлагаемого устройства с представленной структурой и соответствующим программным обеспечением микроконтроллера осуществляется намагничивание и размагничивание изделия из магнитного материала с соответствующим заданным режимом и параметрами, обеспечивая мониторинг параметров на экране дисплея.

Исследование выполнено при финансовой поддержке Комитета по науке МОНКС РА в рамках научного проекта № 18T-2B309, а также в рамках госбюджетной программы Республики Армения "Исследование электромагнитных систем, разработка новых систем".

\section{Литература:}

1. Оганесян А.Т. Режим работы размагничивающего устройства для постоянных магнитов // Известия вузов. Электромеханика.2013.- T. 4.- C. 18-20.

2. Оганесян А.Т., Петросян Н.Н., Питкевич Г.И. Установка для размагничивания постоянных магнитов // Электроника ИНФО.- 2013.- Т. 12 (102).- С. 50-53.

3. Оганесян А.Т. Методы размагничивания ферромагнитных материалов и проектирования электромагнита // Вестник Инженерной академии Армении.- 2013.- Т. 10, № 1.- С. 41-46 (на арм. яз.).

4. Оганесян А.Т., Питкевич Г.И. Обоснование и разработка конструкций размагничивающей установки // Вестник НПУА: Сборник научных статей.- 2015.- Т. 2. С. 390-395.

5. Оганесян А.Т., Барегамян Г.В., Мартиросян Н.В., Хачатрян В.А., Арзанян Р.Г., Азатян Р.Г. Устройство для намагничивания изделий из магнитных материалов // Национальная ассоциация ученых (НАУ).- 2019.- №48, часть 3. С. 37-42.

6. Патент РА на изобретение 2880 А2. Н01F 13/00. Размагничивающая установка / А.Т. Оганесян, Г.И. Питкевич.- 27.10.2014.- 10с.

7. Патент РА на изобретение 3334 А. Н 01F13/00. Устройство для намагничивания изделий из магнитных материалов / А.Т. Оганесян, Н.В. Мартиросян.- 01.10.2019.- 14 с.

8. Патент РА на изобретение 3367 А. Н 01F13/00. Устройство для намагничивания и размагничивания изделий из магнитных материалов / А.Т. Оганесян, Г 